Article

\title{
Converting the Literature of a Scientific Field to Open Access through Global Collaboration: The Experience of SCOAP3 in Particle Physics
}

\author{
Alexander Kohls * (D) and Salvatore Mele \\ CERN, CH-1211 Geneva 23, Switzerland; salvatore.mele@cern.ch \\ * Correspondence: alexander.kohls@cern.ch
}

Received: 23 February 2018 ; Accepted: 3 April 2018; Published: 9 April 2018

check for updates

\begin{abstract}
Gigantic particle accelerators, incredibly complex detectors, an antimatter factory and the discovery of the Higgs boson-this is part of what makes CERN famous. Only a few know that CERN also hosts the world largest Open Access initiative: SCOAP3. The Sponsoring Consortium for Open Access Publishing in Particle Physics started operation in 2014 and has since supported the publication of 20,000 Open Access articles in the field of particle physics, at no direct cost, nor burden, for individual authors worldwide. SCOAP3 is made possible by a 3000-institute strong partnership, where libraries re-direct funds previously used for subscriptions to 'flip' articles to 'Gold Open Access'. With its recent expansion, the initiative now covers about $90 \%$ of the journal literature of the field. This article describes the economic principles of SCOAP3, the collaborative approach of the partnership, and finally summarizes financial results after four years of successful operation.
\end{abstract}

Keywords: CERN; journal flipping; gold open access; particle physics; SCOAP3

\section{Collaboration in Particle Physics (and Its Scholarly Communication)}

Particle physics (also called High Energy Physics-HEP) is the paradigm of international scientific cooperation. After World War II many research centres around the world started building increasingly powerful accelerators. Between 1951 and 1954, twelve European countries founded CERN [1], the European Organization for Nuclear Research, with the objective to "increase international scientific collaboration" and to rebuild their cooperation in the spirit of 'science for peace'. Many decades, successful accelerators, and a couple of Nobel prizes later, CERN now counts 22 Member States [2]. These jointly finance and govern the Organization for the benefit of their scientific community and particle physicists worldwide. Indeed, the CERN scientific program is open to all countries, and over 13,000 researchers from more than 70 nations use the CERN infrastructure by participating in numerous different experiments [3]. The CERN LHC program has come to epitomize big science: a particle accelerator of $27 \mathrm{~km}$ circumference, protons accelerated to almost the speed of light, beams colliding billions of times per second at the core of four large experimental apparatuses, hundreds of petabyte of data recorded, and collaborations of several thousands scientist analysing them. CERN's mission of providing infrastructure for large scale collaborations is one of the pillars of the SCOAP3 Open Access initiative.

Another pillar is the peculiar scholarly communication practice of the field. Particle physics grew fast between the late 1940s and through the 1970s. Experimental physicists gathered at dozens of laboratories around the world, theoretical physicists at hundreds of universities. Accelerators' energy was increased fast, entire zoos of new particles where theorized and discovered. Exchange of information needed to be quick, at a time where the fastest way to communicate was airmail. Traditional scholarly communication practices (i.e., writing an article and waiting for it to appear in 
print on the shelves of academic libraries a couple of years later) was simply not an option to support the scientific vigour of the time. In order to accelerate the distribution of the latest experimental results or new theories, it became common practice instead to mail 'preprints' of scientific papers to the key research centres and physics departments active in the field, at the same time of submission to scholarly journals [4].

With the emergence of e-mail servers in the late 1980s, this system was ready for disruption, both to provide a level playing field (only the most renewed sites would receive all preprints, sent by other researchers hopeful for attention-and mailing lists to which preprints were sent by important institutions would be occasionally pruned to save postage and print, leaving out colleagues at peripheral institutes [5]) and to be able to retrieve on demand interesting preprints, knowing authors and succinct abstracts. Thanks to Paul Ginsparg, then at Los Alamos National Laboratories, arXiv [6] was born in 1991. Following the wider adoption of the idea of the World Wide Web in the HEP community, after its inception at CERN in 1989 [7], arXiv $^{1}$ then became the preprint server with the functionalities expected by a 'Green Open Access Repository' [8] of today. Its universal adoption quickly meant that almost the entirety of the literature then appearing in peer-reviewed journals in the field would appear on the arXiv [9]. After a quarter century, about $60 \%$ of all articles ever written in particle physics have appeared on the arXiv as preprints.

Back to CERN, it is interesting to note that in its original spirit as a locus of open cooperation, the CERN founding Convention [1] includes in the Organization's mission "[...the] sponsoring of international co-operation in nuclear research, including co-operation outside the Laboratories [which] may include in particular [...] the dissemination of information". Moreover, the Convention sets out, that "[...] the results of its experimental and theoretical work shall be published or otherwise made generally available".

In summary, (i) CERN's role to provide infrastructure to the particle physics community; (ii) its spirit of fostering international cooperation; (iii) a scholarly communication environment where universal Green Open Access had since long effectively dis-intermediated the role of journals as tools of dissemination, all together created the conditions for the inception of the SCOAP3 Open Access model. It was driven by the vision of leveraging the cooperative models of particle physics, to convert to Open Access its final peer-reviewed literature at no burden for authors.

This article is structured as follows. After this introduction which has laid out the background of scholarly communication and collaborative infrastructure in the field, Section 2 describes the SCOAP3 business mode, Section 3 illustrates the way SCOAP3 divides across countries its costs, Section 4 presents the collaborative structure of the partnership. Finally, Section 5 discusses the SCOAP3 financial results to date, and Section 6 offers some concluding remarks.

\section{The SCOAP3 Business Model}

The SCOAP3 Business Model was first developed by a dedicated working group ${ }^{2}$ and presented in 2007. The original mission remains fully relevant, and is still the daily driving principle of the initiative. SCOAP3 aims to "provide open and unrestricted access to all HEP research literature in its final, peer-reviewed form. . [and] .. .centralize all OA expenses that will therefore not have to be directly borne by authors and research groups" [10]. In this context, and in the rest of this article, HEP research literature is defined as original research articles that have been submitted by their authors to arXiv under one of its HEP categories ${ }^{3}[11]$.

The legal framework, the financing model, as well as the governance of the initiative follow the well-tested examples of large experimental collaborations at the LHC. Thereby, CERN acts as the

\footnotetext{
http:/ / arxiv.org.

2 The working group consisted of 26 members from the physics and library communities and was mandated by leading European HEP funding agencies, HEP laboratories and library consortia to explore the possibility of converting HEP scientific publishing to Open Access [10].

3 hep-ex, hep-lat, hep-ph, hep-th.
} 
'Host Organisation' of the initiative in the same way that it hosts experiments in accordance with its principles [1]. A multitude of institutions, in this case mainly academic libraries, then use this infrastructure to achieve an overarching objective which only their worldwide collaboration and financial cooperation could make possible. Through the transfer of this knowledge and governance model, academic libraries, and their worldwide community, can be empowered to affect global changes in Open Access.

The key Open Access innovation, and ultimately the success, of SCOAP3 is indeed the continuous and constructive tripartite collaboration of the library community, national funding agencies and commercial and society publishers of high-quality HEP journals. All these participants are part of the SCOAP3 'recirculation of funds' business model, displayed in Figure 1 and described in the following.

(1) CERN, for the benefit of SCOAP3, enters into contracts with publishers of HEP journals (again following the example of experiments hosted at CERN, on whose behalf CERN contracts). Depending on the journal's fraction of HEP content, the contract may cover the entire journal or only the HEP fraction. Publishers are centrally paid for their services by SCOAP3. All HEP articles are immediately published Gold Open Access under a Creative Commons Attribution (CC-BY) licence ${ }^{4}$ and authors retain the copyright in their work.

(2) Under the terms of the SCOAP3 contracts, participating publishers reduce subscription fees for all their customers, in a way commensurate with the content becoming Open Access. A reconciliation process took place before launching the operation to determine the exact amounts of reductions under mutually accepted principles. This process can be complex when SCOAP3 journals form part of a large package deal or consortia arrangement, and the successful conclusion creates the financial leverage to support then the operation.

(3) The reduction of subscription fees releases funds in the library system that SCOAP3 partners use to pay their contributions to the initiative. As they redirect funds previously spent to access content that is now Open Access, initial participation in SCOAP3 is often cost-neutral for individual libraries. This is an important change in the role of libraries, and one increasingly gaining attention. Through a synoptic view of subscription investment, and Open Access opportunities, libraries can be instrumental in the process of making published content immediately available Open Access, both from researchers from their institutions and globally.

(4) The publication process for researchers does not change when a journal becomes part of SCOAP3. Authors do not need to pay Open Access fees, nor need to be distracted by any administrative matter. Everything is handled centrally, without any interaction with the authors who, 'magically' comply with even the strictest institutes 'or funders' Open Access mandates ${ }^{5}$. By design, this is a departure, from so called 'author-pays' models where authors, or their institutions directly, cover publication fees. Creating the 'invisible infrastructure' SCOAP3, and in a comparable way, also the emerging national and institutional-wide agreements with selected publishers, aim to realise the largest amount of advantages for authors and readers in parallel. This, in turn, allows a fact-based approach for institutions, and libraries in their new role of managing Open Access therein, to articulate the shifting of publication costs, and process, to a central institutional point rather than the author level.

(5) In some countries, national funding agencies support the initiative with additional financial contributions to SCOAP3 beyond the contributions from academic libraries. This is particularly relevant in countries that are very active in particle physics as discussed in Section 3.

(6) A guiding principles of SCOAP3 is to remove any barriers or burden for authors to achieve Open Access, and give to any reader access to any article in the field. This creates a possible financial shortfall as some institutes in particular countries, or some countries overall, could choose not to participate to the initiative, without any disadvantages for their authors. CERN,

4 https://creativecommons.org/licenses/by/4.0/. This license, and its previous version, are used for all SCOAP3 articles. They allow the widest possible dissemination and reuse of the work.

5 E.g., the Research Councils UK [12] or the Austrian Science Fund (FWF) [13]. 
as the host organization of SCOAP3, initially covers such shortfalls while the initiative is still growing. Indeed, from its start in January 2014, more than 1300 new universities from 28 countries as well as 2 intergovernmental organizations joined SCOAP3, consistently reducing this shortfall as the realization of Open Access opportunities matures globally.

\section{SCOAP $^{3}$ Model}

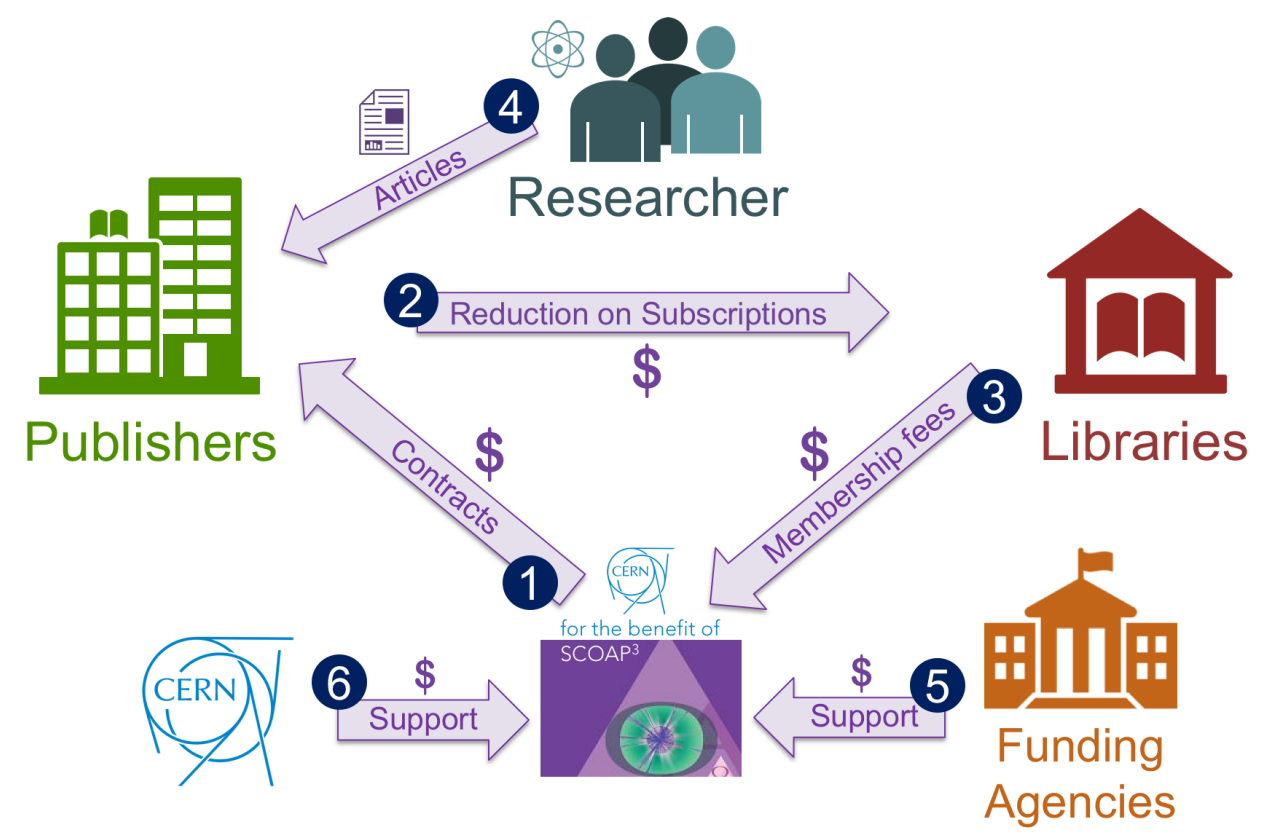

Figure 1. Main stakeholders and financial flows in the SCOAP3 Business Model.

\section{The SCOAP3 ‘Fair Share' Principle}

A key factor in the SCOAP3 partnership is a commonly-accepted and unambiguous mechanism to allocate costs across literally thousands of participating libraries. SCOAP3 introduced a 'fair share' principle, based both on the tradition of academic libraries consortia, and inspiration from the budgets of large-scale HEP experiments.

The cost-allocation scenario starts from two observations. The first is that the costs of peer-review are now sustained at the author-side rather than the reader-side, and therefore need to be correlated with the quantity of authorship. The second is that SCOAP3 contracts between CERN and publishers are designed as service contracts, suggesting that costs be allocated in proportion to the usage of such service, which again points to the quantity of authorship.

Both large-scale collaboration, with thousands of authors in about $10 \%$ of HEP papers, and wide-spread multi-institute collaboration across countries, make it impractical to allocate costs based, say, on first or corresponding authors.

SCOAP3 adopted such an allocation at country level. Each country would be responsible for a fraction of the total budget in proportion with the number of their 'signatures' in the literature, i.e., individual authors affiliated to institutes in that country. The detailed mechanics of this calculation are described by Krause, Lindqvist, Mele [14], and in particular the way to fairly resolve frequent cases of multiple affiliations.

All SCOAP3 participating countries have agreed that their 'fair share' also includes an additional contribution above the volume of their publication, to fairly give Open Access opportunities to researchers from low- and medium-income countries, whose institutions cannot be reasonably expected to have the means to support the initiative. 
While allocating costs of an Open Access initiative based on authorship may seem like an obvious approach, it could lead to financial imbalances in the SCOAP3 vision of converting an entire field to Open Access. Indeed, contributions to SCOAP3 are intended to be financed by redirecting funds previously used to subscribe to SCOAP3 journals. While this model works well at a global scale, there could be differences between the aggregate amount of reductions in subscription fees of all institutions in a country, compared to this country's 'fair-share' contribution.

In particular, countries with a relatively high research intensity in the field, might face a funding gap, as the aggregate reductions in academic libraries' subscriptions are not sufficient to support a comparatively high 'fair share'.

To address the funding gaps in some countries with insufficient redirected library funds, SCOAP3 collaborates with several funding agencies [15]. Most libraries continue to contribute on a cost-neutral basis while a central agency tops up the missing funds. This is particularly attractive for funding bodies with a vision to implement Gold Open Access. The fact that most Gold Open Access costs are already covered by the re-direction of subscriptions, makes the actual costs for agencies relatively low compared to full payment of publication fees, often called Article Processing Charges ${ }^{6}$.

At this moment, such arrangements are not present in all countries with a funding gap. In some, academic libraries have made an effort to contribute beyond their aggregate reductions at the service of their research communities. In others, a gap persists and is temporarily filled by CERN.

Finally, as mentioned in Sections 4 and 5 below, some countries are not yet engaging with SCOAP3 and their 'fair share' is currently also met by CERN.

\section{The SCOAP3 Collaboration Structure}

The SCOAP3 organisation closely mimics that of the large experimental collaborations at CERN. At the time of writing, SCOAP3 consists of more than 3000 libraries from 43 countries [15]. To accommodate widely varying national academic structures, research libraries or funding agencies join the collaboration in several ways. In many countries, one central organisation, most often an existing library consortium, represents all research libraries in the country. In other countries, several established consortia participate in parallel. Funding agencies, orchestrating the SCOAP3 participation, might either participate in their own right as additional partners in that country, or support financially the country's participants. At the moment of writing, beyond nation states, also three intergovernmental organisations with a stake in the field, participate in SCOAP3 with the same rights and obligations as individual countries. The first is CERN as a partner, through its library. The second is the International Atomic Energy Agency, IAEA. The third is the Joint Institute for Nuclear Research, JINR, an organisation similar to CERN, that represents some of its 18 Member States in the initiative. The different participation models are shown in Figure 2.

As for all large multilateral endeavours, good and participative governance is at the core of the SCOAP3 initiative. It is interesting to describe as, to our knowledge, this is the first time a large Open Access initiative has adopted a similar model. All participating countries are represented in the SCOAP3 Governing Council [16] which steers the strategic direction of SCOAP3, establishes the rules of the collaboration, and discusses all key financial aspects (e.g., new contracts with publishers). Every country or intergovernmental organisation is represented at the Governing Council. Following the collaborative spirit SCOAP3 is built on, the partnership aims for unanimity for all decisions.

The Governing Council appoints the members of the SCOAP3 Executive Committee. This board follows the geographical and institutional diversity of the SCOAP3 partnership and is responsible for the operation of the initiative and closely collaborates with the SCOAP3 Operations team at CERN. The Executive Committee receives support from dedicated community working groups. Such working

6 A fee usually charged on a per-article basis by the publisher to make a publication available Open Access. It covers the article production costs as no subscription fees can be generated for the Open Access content [8]. 
groups are also established by the Governing Council for a specific purpose (e.g., financial audit, repository services, survey of strategic opportunities) [16].

The role of CERN as the host organisation of SCOAP3, comes with some specific responsibilities. CERN provides in-kind resources such as operations personnel, technical and administrative infrastructure, and hosts the regular governance meetings. At the time of writing, the CERN SCOAP3 Operations team employs about 1.5 FTE staff to assure the operation of the initiative. To assure constant alignment of the SCOAP3 vision and CERN's own Open Access approach, CERN is entitled a dedicated representative in the SCOAP3 governing bodies. Beyond CERN's staff investment, some small IT infrastructure and the management of a dozen service contracts, the the administrative overheads of SCOAP3 are comparable to those of any membership organization which is coordinating, and invoicing, about four dozen partners. Indeed, a key part of the SCOAP3 model is the indispensable nation-by-nation role of contacts which organise their domestic community and liaise with the international governance.

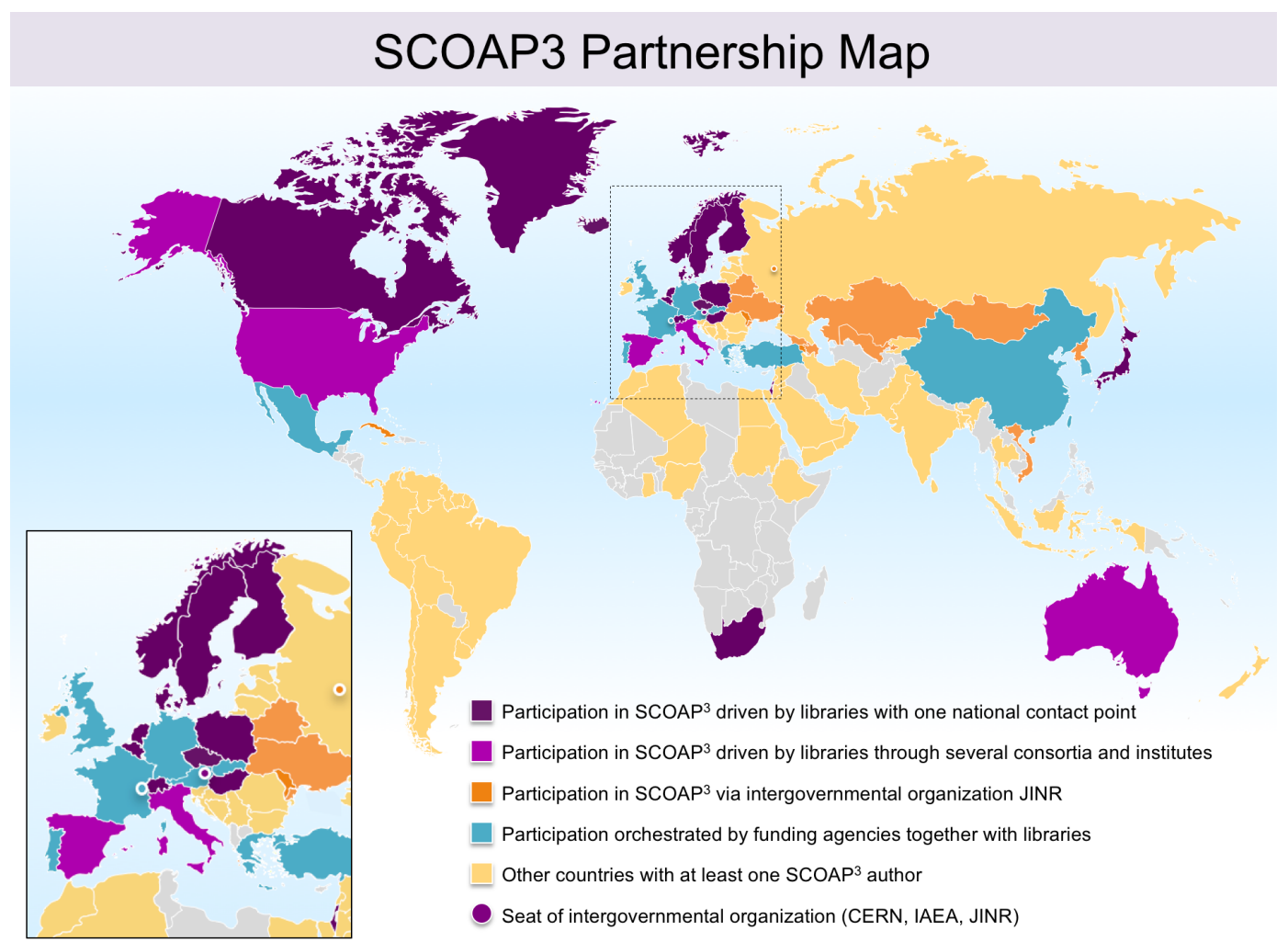

Figure 2. SCOAP3 Partner Countries by type of participation as well as countries with at least one author publishing in SCOAP3 journals (as of February 2018).

\section{Financial Results}

As a result of a competitive tendering process, CERN, for the benefit of SCOAP3, entered into contracts with 11 commercial and society publishers for its first 3-year cycle (2014-2016) as shown in Table 1. These contracts determine nominal journal-specific Article Processing Charges (APCs). However, the SCOAP3 arrangements have a very important difference with respect to a simple agreement to cover APCs for a set of authors. To ensure contracts fit within the overall partnership's budget, SCOAP3 has introduced a capping mechanism. If the number of published articles in a journal exceeds a certain annual maximum, originally defined as the volume of publications in that journals within some yearly growth, every additional article has then to be made Open Access at no additional cost [17]. As a result, SCOAP3 contracts focus on the notion of a total amount required to convert 
an entire journal (or the HEP fraction thereof) to Open Access. Between 2014 and 2016, SCOAP3 supported the publication of 13,368 articles [18].

Table 1. List of publishers and journals participating in the first 3-year cycle of SCOAP3 (2014-2016), alongside the nominal charge per article (effective charges differ, and are calculated as described in the text), the fraction of the journal covered by SCOAP3 and the number of articles covered over the first three years of the initiative.

\begin{tabular}{|c|c|c|c|c|}
\hline Publisher & Journal & $\begin{array}{l}\text { Nominal } \\
\text { APCs }\end{array}$ & $\begin{array}{c}\text { HEP } \\
\text { Coverage }\end{array}$ & $\begin{array}{l}\text { SCOAP3 Articles } \\
\text { 2014-2016 }\end{array}$ \\
\hline Elsevier & Nuclear Physics B & 2000 USD & $100 \%$ & 1008 \\
\hline Elsevier & Physics Letters B & 1800 USD & $100 \%$ & 2654 \\
\hline Hindawi Publishing & Advances in High Energy Physics & 1000 USD & $100 \%$ & 512 \\
\hline $\begin{array}{l}\text { IOP Publishing/Chinese } \\
\text { Academy of Sciences }\end{array}$ & Chinese Physics C & 1000 GBP & $7 \%$ & 91 \\
\hline $\begin{array}{l}\text { IOP Publishing/German } \\
\text { Physical Society }\end{array}$ & New Journal of Physics & 1200 GBP & $3 \%$ & 25 \\
\hline IOP Publishing/SISSA & $\begin{array}{l}\text { Journal of Cosmology and } \\
\text { Astroparticle Physics }\end{array}$ & 1400 GBP & $31 \%$ & 654 \\
\hline Jagiellonian University & Acta Physica Polonica B & 500 EUR & $22 \%$ & 56 \\
\hline $\begin{array}{l}\text { Oxford University Press/ } \\
\text { Japanese Physical Society }\end{array}$ & $\begin{array}{l}\text { Progress of Theoretical and } \\
\text { Experimental Physics }\end{array}$ & 1000 GBP & $36 \%$ & 255 \\
\hline $\begin{array}{l}\text { Springer/ } \\
\text { Italian Physical Society }\end{array}$ & European Physical Journal C & 1500 EUR & $100 \%$ & 1830 \\
\hline Springer/SISSA & Journal of High Energy Physics & 1200 EUR & $100 \%$ & 6283 \\
\hline
\end{tabular}

Between 2014 and 2016, the SCOAP3 partnership disbursed a total 13.8 million Euros to publishers for making 13,368 articles Open Access. The average investment per article ${ }^{7}$ was of 1032 Euros per article over the first three years. This average investment per article for journals in this 'quality' range 8 compares positively to other Open Access initiatives ${ }^{9}$.

It is important to note that all running costs of SCOAP3 beyond the payments to publishers are borne by CERN, within its mission of providing infrastructures for the field and its commitment to Open Access. All governance roles are non-remunerated and on a voluntary basis. Therefore, the actual cost for the SCOAP3 partnership itself is limited to the payments to publishers.

More than three-quarters of the 13.8 million Euros of Open Access fees (2014-2016) were financed by the re-direction of funds previously used for subscriptions in participating libraries. Funding agencies in some research-intensive countries contributed a top-up of these funds, if redirected subscription funds from libraries were not sufficient. In aggregate, these two sources represent $92 \%$ of the SCOAP3 financing.

7 The notion of investment per article (IPA) might be in this context a more interesting one than an APC for two reasons. The first is that the structure of the SCOAP3 contracts, and their summed investment from the partnership, increasingly diverges from the notion of paying a single fee for a single article in a ('hybrid') journal. The second is that, effectively, access and reuse of the articles will stand indefinitely after this initial public 'investment' in such a common good.

8 We use this word encompassing both the perception of the HEP community, as well as objective indicators of quality based on citation counts.

9 Recent studies, analysing actual Open Access fees paid by European institutions, calculated average Article Processing Charges in the range of 1900-2000 Euros [19,20]. 
The missing $8 \%$ can be attributed to a few individual institutions, and a few countries, not yet participating in SCOAP3 but having a significant HEP authorship (as presented in Figure 2). For the initial phases of SCOAP3, CERN is covering this shortfall under the guidance of its own governance.

SCOAP3 extended its operation for a second 3-years cycle, from 2017 through 2019. A total of 8 journals are covered in this period, with article numbers growing to an expected total above 15,000 , for a maximum expenditure of 14.7 million Euros. Therefore, the average investment per article is expected to remain stable around 1000 Euros [21].

\section{Conclusions and Recent Developments}

Thanks to the tripartite involvement of academic libraries, funding agencies and publishers, in a multi-lateral international collaboration hosted at CERN, SCOAP3 has been successful in delivering its objective "to provide open and unrestricted access to all HEP research literature..." [10]. In the following, this statement is quantitatively assessed, and compared to recent developments.

The total volume of HEP journal publications can be estimated as follows. All relevant literature in the field is indexed in the InspireHEP database ${ }^{10}$. For the year 2017, InspireHEP lists 7023 HEP articles (following the arXiv-based, author-driven, self-categorization explained in Section 2) [22]. About two dozen journals have a significant amount of HEP articles so defined. A long tail of journals publishes less than $25 \mathrm{HEP}$ articles per year ${ }^{11}$. It is practically impossible to convert such a long tail to Open Access, and we ignore this small fraction of articles. From the remaining 6640 articles, 53\% were supported by SCOAP3 during the first year of its second cycle, as detailed in Table 2.

Table 2. 2017 High Energy Physics (HEP) articles by journal group.

\begin{tabular}{ccc}
\hline Journal Group & 2017 HEP Articles & Share \\
\hline SCOAP3 Journals & 3499 & $53 \%$ \\
APS Journals & 2400 & $36 \%$ \\
Other Journals & 741 & $11 \%$ \\
\hline
\end{tabular}

The largest outstanding amount of article was published in journals by the American Physical Society. In April 2017, CERN and the American Physical Society (APS) announced that from January 2018, APS would participate in SCOAP3 with the HEP content of three journals [23] and therefore increasing the SCOAP3 coverage to $89 \%$ of the journal literature in the field.

In summary, the vision of SCOAP3 has been almost entirely realized. In a recent public webinar, the SCOAP3 governance announced that it is investigating which opportunities could exist, to extend its Open Access model to cover some of the remaining $11 \%$ of journal publications.

Acknowledgments: The authors wish to thank all members of the SCOAP3 governance, and in particular the current and former members of the SCOAP3 Executive Committee, for their shared vision, intellectual contributions, moral support and financial commitment. SCOAP3 would not be possible without the generous support of many colleagues in various CERN services which contributed expertise and enthusiasm over a decade of preparation and operation of this initiative.

Author Contributions: Both authors worked on this manuscript and carried out the analysis and discussion jointly.

Conflicts of Interest: The authors are members of CERN personnel, and CERN is the Host Organisation of SCOAP3. Both are directly involved in the initiative: A.K. holds the position of SCOAP3 Operations Manager; S.M. led the initiative before the start of operations, and is appointed by CERN to the SCOAP3 governing bodies.

10 https://inspirehep.net.

11383 articles published in 77 journals. 


\section{Abbreviations}

The following abbreviations are used in this manuscript:

$\begin{array}{ll}\text { APC } & \text { Article Processing Charge } \\ \text { APS } & \text { American Physical Society } \\ \text { CC-BY } & \text { Creative Commons Attribution License } \\ \text { CERN } & \text { European Organization for Nuclear Research } \\ \text { FTE } & \text { Full-Time Equivalent } \\ \text { HEP } & \text { High-Energy Physics } \\ \text { IAEA } & \text { International Atomic Energy Agency } \\ \text { IPA } & \text { Investment Per Article } \\ \text { JINR } & \text { Joint Institute for Nuclear Research } \\ \text { LHC } & \text { Large Hadron Collider } \\ \text { OA } & \text { Open Access }\end{array}$

SCOAP3 Sponsoring Consortium for Open Access Publishing in Particle Physics

\section{References}

1. CERN Convention for the Establishment of a European Organization for Nuclear Research. CERN, 1953. Available online: https://council.web.cern.ch/en/content/convention-establishment-europeanorganization-nuclear-research (accessed on 20 February 2018).

2. CERN Member States. Available online: http://www.webcitation.org/6xNGDH2oU (accessed on 20 February 2018).

3. CERN Distribution of all CERN Users by Location of Institutes on 5 July 2017. OPEN-PHO-CHART-2017-007. Available online: https:/ / cds.cern.ch/record/2290407 (accessed on 20 February 2018).

4. Heuer, R.-D.; Holtkamp, A.; Mele, S. Innovation in Scholarly Communication: Vision and Projects from High-Energy Physics. Inf. Serv. Use 2008, 28, 83-96, doi:10.3233/ISU-2008-0570.

5. Goldschmidt-Clermont, L. Communication Patterns in High-Energy Physics. HEP Libr. Webzine, $2002,6$. Available online: http:/ / webzine.web.cern.ch/webzine/6/papers/1/index.html (accessed on 21 February 2018).

6. Editorial: Keep Posting. Nat. Phys. 2016, 12, 719, doi:10.1038/nphys3862. Available online: https://www. nature.com/articles/nphys3862 (accessed on 21 February 2018).

7. Berners-Lee, T.J. Information Management: A Proposal. CERN, 1989. CERN-DD-89-001-OC. Available online: https: / cds.cern.ch/record/369245 (accessed on 20 February 2018).

8. Suber, P. What is Open Access. In Open Access; MIT Press: Cambridge, MA, USA, 2012; pp. 1-27, ISBN 978-02-6230-252-4.

9. Gentil-Beccot, A.; Mele, S.; Brooks, T.C. Citing and Reading Behaviours in High-Energy Physics. Scientometrics 2010, 84, 345-355, doi:10.1007/s11192-009-0111-1.

10. Bianco, S.; Ellestad, O.H.; Ferreira, P.; Friend, F.; Gargiulo, P.; Hanania, R.; Henrot-Versille, S.; Holtkamp, A.; Igo-Kemenes, P.; Jarroux-Declais, D.; et al. Towards Open Access Publishing in High Energy Physics: Report of the SCOAP3 Working Party. CERN, 2007. CERN-OPEN-2007-015, ISBN 978-92-9083-292-8. Available online: https: / scoap3.org/files/Working_Party_Report.pdf (accessed on 21 February 2018).

11. SCOAP3 Invitation to Tender-Technical Specification. CERN 2012. Available online: https://scoap3.org/ files/Technical_Specification.pdf (accessed on 20 February 2018).

12. RCUK Policy on Open Access. Available online: http://www.rcuk.ac.uk/documents/documents/ rcukopenaccesspolicy-pdf/ (accessed on 17 January 2018).

13. FWF Open Access Policy. Available online: http://www.webcitation.org/6xNFwtASf (accessed on 20 February 2018). 
14. Krause, J.; Lindqvist, C.M.; Mele, S. Quantitative Study of the Geographical Distribution of the Authorship of High-Energy Physics Journals. CERN, 2007. CERN-OPEN-2007-014. Available online: https://cds.cern. ch/record/1033099 (accessed on 20 February 2018).

15. SCOAP3 Participating Countries. Available online: http://www.webcitation.org/6xNFlBz9R (accessed on 20 February 2018).

16. What is SCOAP3: Governance. Available online: http://www.webcitation.org/6xNFpARKE (accessed on 20 February 2018).

17. Romeu, C.; Gentil-Beccot, A.; Kohls, A.; Mansuy, A.; Mele, S.; Vesper, M. The SCOAP3 Initiative and the Open Access Article-Processing-Charge Market: Global Partnership and Competition Improve Value in the Dissemination of Science. CERN, 2016. CERN-OPEN-2014-037, doi:10.2314/CERN/C26P.W9DT. Available online: https:/ / cds.cern.ch/record/1735210/ (accessed on 20 February 2018).

18. SCOAP3 Phase 1 Journals. Available online: http://www.webcitation.org/6xNG2CUt1 (accessed on 20 February 2018).

19. Ahlborn, B.; Ambler, C.; Andrae, M.; Apel, J.; Becker, H.-G.; Bertelmann, R.; Beucke, D.; Blume, P.; Blumtritt, U.; Braun, K.; et al. Datasets on Fee-Based Open Access Publishing across German Institutions; Bielefeld University: Bielefeld, Germany, 2018. doi:10.4119/UNIBI/UB.2014.18.

20. Shamash, K. Article Processing Charges (APCs) and Subscriptions-Monitoring Open Access Costs. JISC. 2016. Available online: https:/ / www.jisc.ac.uk/sites/default/files/apc-and-subscriptions-report.pdf (accessed on 15 January 2018).

21. SCOAP3 Forum 2017 Presentation. Available online: https://scoap3.org/wp-content/uploads/2017/12/ Webinar-Dec-2017.pdf (accessed on 15 January 2018).

22. InspireHEP. Available online: http:/ / inspirehep.net/?ln=en (accessed on 17 January 2018).

23. SCOAP3 News: APS Joins SCOAP3. Available online: http://www.webcitation.org/6xNFQb5iD (accessed on 20 February 2018).

(C) 2018 by the authors. Licensee MDPI, Basel, Switzerland. This article is an open access article distributed under the terms and conditions of the Creative Commons Attribution (CC BY) license (http:/ / creativecommons.org/licenses/by/4.0/). 